The Gap Year for Geographers: Effects and Paradoxes

GEORGE ALAN BLACKBURN, GORDON CLARK \& DAVID PILGRIM

Department of Geography, Lancaster University, Lancaster LA1 4YB, UK.

Correspondence:

Dr Alan Blackburn, Tel: 01524 592775. Fax: 01524847099.

E-mail: alan.blackburn@lancaster.ac.uk.

Dr Gordon Clark, Department of Geography, Lancaster University, Lancaster LA1 4YB. Tel: 01524 593740. Fax: 01524 847099. E-mail: g.clark@lancaster.ac.uk. 


\title{
The Gap Year for Geographers: Effects and Paradoxes
}

\begin{abstract}
This paper examines why the growing gap-year phenomenon is important for university geography departments in the context of education and employment. The research examines the scale and types of gap years, and their effects on students. The study uses a multi-actor approach comprising information from national statistical sources, university departments, students who have taken gap years and commercial gap-year providers. The paper draws some lessons for geography departments such as the need to systematically record the effects of a gap year. It highlights some paradoxes of any expansion of the gap-year market; for example, that expansion may reduce the benefits of the gap-year experience and may narrow the types of gap year taken. Issues of social exclusion also arise.
\end{abstract}

KEYWORDS Gap year, transitions, skills, inclusion. 


\section{INTRODUCTION}

The gap year taken by students between school and university is not a new phenomenon but it has become more frequently remarked on in the last decade. Media attention has created the impression of a powerful trend or fashion. Yet there are good educational reasons for critically evaluating the numerous academic, personal and employment benefits claimed for the gap-year experience. The gap year has scarcely been researched seriously, either in terms of its effects on students or for university departments. This paper reports on some initial research on gap years which tackles these deficiencies in our understanding. The paper examines and compares the views on gap years of some of the key actors (students, departments and gap-year providers). It draws some lessons for university departments of geography from the development of the gap-year phenomenon; and highlights paradoxes in the expansion of the gap-year market which require further research.

\section{PEDAGOGIC AND PUBLIC INTEREST IN GAP YEARS}

The educational interest in gap years springs for three sources. First, the Quality Assurance Agency's Geography benchmark statement says that in the UK all geography degrees should help students to develop certain personal attributes and social skills (QAA, 2000). It is arguable a priori that a gap year might, depending on its content, improve some of the intellectual skills of the graduate geographer identified in the benchmark statement notably decision making, taking responsibility for one's life and key skills such as handling interpersonal situations (ibid. p5). Some of the personal attributes and social skills required are often particularly difficult to include explicitly in a degree programme, yet they could be at the heart of the gap-year experience. These attributes include motivation, autonomy, self-awareness, self motivation, flexibility and adaptability. If nothing else, the gap year could be part of that training in independence which the Benchmark Statement sees as the hallmark of the geography dissertation (ibid. p6). A gap year 
could enhance such personal qualities in students and, as this occurs before university, it could improve students' performance in higher education. Should university geography departments therefore welcome the gap-year phenomenon for its better prepared students, or are there problems with this argument? This paper explores this question.

The second interest in the gap year is in terms of employability skills. The Association of Graduate Recruiters (1995) noted that employers want new recruits to possess, in addition to subject skills and knowledge, proven abilities in time management, problem solving and communication skills. The Geography Discipline Network has produced guides to embedding key skills in geography at university, notably in this context the guides on work-based learning (Chalkley, 2000) and problem solving (Gardiner and Hughes, 2000). Jenkins and Healey (1995) have collected together several papers on forging links between degree schemes and the world of work. Clearly both these agendas would be helped by students whose starting points in paid work and problem solving were higher than currently, and a gap year might be a pre-university device to achieve this. A reflective appreciation of the benefits derived from a gap year may improve a student's curriculum vitae in ways that conventional degree programmes could find difficult in terms of specific achievements teaching time is necessarily limited. Hence students who have taken a gap year might improve a department's employability record, to both the department's and their students' benefit.

The third educational interest in the gap year stems from the work of Dweck (1999) on selftheories. Her argument is that academic performance will be improved if students have adopted an incrementalist view of their abilities (i.e. that improvement is possible and intelligence is not a fixed entity) and when they have concluded that control over their performance is an internal matter (i.e. one can improve one's performance independently of such external forces as luck or fate). Additionally such self-views may make one more employable. Arguably a successfully planned and executed gap year will enhance a student's sense of achievement, persistence and self- 
confidence. Of course, Dweck's views are hypotheses and in practice are hard to evaluate, though Yorke and Knight (2002) describe one survey's results. If gap years can edge students further towards, in Dweck's terminology, a self-efficacy position, then their general educational effect could be highly beneficial.

Anecdotally interest in gap years has become much higher than previously, in part due to Prince William's gap year with Operation Raleigh in Chile. Between August 1998 and August 2002 The Times, Daily Telegraph, Independent and Guardian between them had 1365 references to gap years. There has been a Gap Year Magazine published since 2000 by the Gap Year Company which is distributed to every UK school and university. The researchers found 18 books of a selfhelp variety in high-street bookshops, and Amazon (the Internet bookseller) listed 22 gap-year books for sale in August 2002. There are several 6- and 12-month insurance policies for young travellers now available. There was a 90-minute debate on gap-year students in the House of Commons on 1 July 1998. The Chief Executive of UCAS has warmly supported gap years (UCAS, 2001) as has Margaret Hodge, the Minister for Employment and Equal Opportunities (Year Out Group, 2000). The public profile of the gap year is certainly high.

There is also much stereotyping - the gap-year student is pictured as a backpacker in Australia, or something similar. Vandome (2002) reminds us of the wide range of activities that can be pursued during a gap year:

- $\quad$ take a break from studying;

- get work experience;

- $\quad$ spend a year doing something exciting;

- $\quad$ see new cultures;

- get away from home for a while before embarking upon a university course;

- $\quad$ earn some money to make the university experience more comfortable; 
- take time to ensure the correct decision on what further study to embark upon;

- gain skills in planning time, activities and finance.

This wide range raises the question of what are the effects of a pre-university gap year and how this impinges on how university geography departments plan their curriculum.

In this paper we are not considering the effects of a gap year within the scope of a degree scheme in the form of a placement year. There is evidence (Clark et al., 1990) that Coventry's well known sandwich year has effects on maturity similar to those claimed for the pre-university gap year, as well as acquiring new skills, application of knowledge and career-mindedness which come from its being embedded in a degree programme. Nor does this paper consider the relative effects of the gap year taken after graduation.

\section{THE SCALE OF THE GAP-YEAR PHENOMENON}

It is surprisingly difficult to say how many young people are taking a gap year (and hence whether the practice is becoming more common as is alleged) let alone finding out what sorts of people are taking a gap year. The problems are matters of definition. For this research the authors are looking primarily at people who have taken a year out between completion of A-Levels (and equivalents) and the beginning of a university geography course.

There is no central public or commercial register of those taking a gap year. The Universities and Colleges Admissions Service (UCAS) records only those applying for university in one year for entry in the following year (the so-called 'deferred entry'). UCAS does not record what these people are doing during the gap year - students may defer for financial or health reasons which fall outside one's normal definition of a gap year. Nor does UCAS record the gap-year students who delay their 
university application until during the gap year itself. Nor can it tell which students never take up their university place after their gap year. Figure 1 shows the relationships among these various categories. UCAS data may not be reliable for those who decide very late in the admissions cycle either to take a gap year or to cancel one they had planned. This makes the task of quantifying the number of gap-year students challenging, and therefore data interpretation needs to bear this in mind.

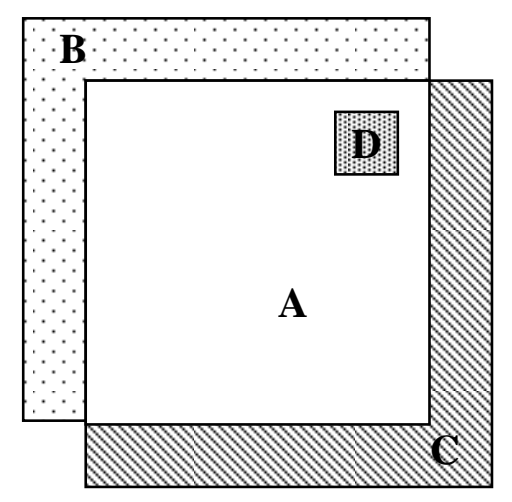

FIGURE 1 Defining a gap year

$\mathrm{A}=$ those who defer entry and take a gap year; $\mathrm{B}=$ those who defer entry for reasons other than taking a gap year; $\mathrm{C}=$ those who take a gap year but do not defer entry (they apply to university during their gap year); $\mathrm{D}=$ those who defer entry and take a gap year but do not go on to enter university. UCAS records deferrals (i.e. A + B + D). Gap-year students are A + C + D.

The UCAS data show that among the applicants in 2000 12,333 women and 10,944 men deferred entry. The total number of people deferring has been gradually increasing in recent years. Among UCAS applicants in 1994 14,530 (5.4 per cent of them) deferred entry for a year and both the number and percentage of deferrals has risen steadily each year to 23,277 (6.9 per cent of applicants) in 2000 .

These data can be further examined in comparison with figures presented to the House of Commons debate on gap years. It was suggested that in 1998 universities admitted 55,000 19-year-olds (i.e. 
entry deferred for one year) and 20,000 20-year-olds (entry deferred for two years) (Parliamentary Debates, House of Commons, 1997-98, p80). This is a different definition of a gap year and nearly twice as large a figure as the first measure given above. This supports the idea that the group who apply for university entry during their gap year may be quite a large one and that UCAS data on deferrals may under-estimate the scale of the phenomenon.

Popular imagination would suggest that geographers might be keener on exploring new environments and cultures than those planning on studying most other subjects and so might be more likely to take a travel-oriented gap year. Data on the deferral rate by department at Lancaster University for 2001 (the only reliable data on gap years by subject which was available to the authors) show a University deferral rate of 7.6 per cent whereas among applicants to Geography degrees it was 10.8 per cent, the fourth highest of the major admitting departments at Lancaster.

The statistical evidence on gap years is not highly informative. However, it does indicate that while only a small minority of students take a gap year, slightly more women do than men, the number taking a gap year is rising and gap years are to a limited extent more prevalent among geography students. Overall the statistical sources do not tell us much about gap years.

\section{ADMISSIONS TUTORS' VIEWS}

There is a little evidence of the views on gap years among the different professions. Some fields, notably engineering, advocate a year in industry before studying the subject at university (Royal Academy of Engineering, n.d.). Conversely, a study in the British Medical Journal showed that applicants to medical schools requesting a gap year were significantly less likely to be offered a place than others (McManus, 1998). The surmise was that this was interpreted by admissions tutors as indicating a lack of commitment to a subject with a very long training period. To test this, a 
survey was carried out of admissions tutors at Lancaster University designed to see if there were any inter-disciplinary differences in how gap years are viewed. A short questionnaire was e-mailed to admissions tutors - 22 of the 50 replied. This enquired about their department's experience of gap-year students, and their views on the effects they saw gap years as having on their new Year 1 students.

No department had surveyed their gap-year students and all the tutors' views were based on anecdote or impression. This itself is an important finding; the topic is under researched and so the tutors' views were impressionistic to a greater or lesser extent. Across all the disciplines they had no data on the numerical trends in gap years but thought there had been a small increase. Nearly every department indicated that their gap-year students were either travelling or working to pay for university, or in several cases, a mixture of both. Some of the more interesting and revealing comments about student activities are outlined below.

- $\quad$ "Working (some do organised gap year work with e.g. Arthur Andersen), travelling (often with some definite purpose e.g. Raleigh), combinations of the above. They all seem to have a definite plan that appears to have been well worked out - none are just dossing about." (Management)

• "They tend to spend time in the country of the language they intend to study." (Modern Languages)

- $\quad$ "They usually talk in terms of a year abroad dispensing benefits to the disadvantaged and broadening their horizons." (Politics) The somewhat sceptical tone of this comment was intentional.

- The response from Geography was a positive one differing from those in other subjects only by focusing specifically on the maturity and experiential value of the travel abroad element within the gap year. 
Only Physics, perhaps a particularly linear and cumulative subject, was not in favour of their students taking time out. "The gap year should be avoided if at all possible since many students have difficulty in re-calling material from school as it is, and the gap year just makes matters worse for them, especially as far as Maths is concerned. There is also a danger that some students may not enter university at all."

The majority of the replies took a positive opinion of the gap year in the academic sense, giving more weight to the benefits flowing from enhanced personal development than to forgotten factual material or rusty study habits. Management went as far as to say that "perhaps [gap years] should be compulsorily!"

Tutors had some difficulty in pinning down clear effects from a gap year because they had not investigated this. Many felt that the benefits of taking a gap year were more to do with personal development than academic performance, which might produce a more confident and effective job seeker. Several respondents felt that students might be more mature and better able to study effectively as a result, though History and Politics were sceptical - they questioned whether the people who take gap years are those who already possess the skills that will make them attractive to employers. Mathematics said they would not recommend a year out to anyone who felt they were ready to take on university, since the benefits might then be outweighed by the disadvantages associated with 'academic amnesia'. The replies from the Management School saw the gap year as something to be encouraged, although the importance was also recognised of taking a year out only if one had plans and ambitions rather than simply taking time out for its own sake.

Overall the departmental responses were sweeping and bland, lacking insight, founded on conjecture and popular image rather than hard evidence from surveys, and only occasionally critical 
or sceptical. For detail on gap-year activities and their effects, a survey of students who had taken a gap year was essential.

\section{GAP-YEAR STUDENTS' VIEWS}

An in-depth discussion on their gap-year experiences was held with geography students at Lancaster University who had been on one. To keep these focus groups to the ideal size for participation, two focus groups were held. The four students in the first group were Liz, Tim, Emma and Helen; in the second group were Phil, Glen, Malcolm, Matthew and Emma(2). Together they represented most of the current students who were known to have taken a gap year. The semistructured focus-group conversations were recorded on audio tape and left to flow as much as possible so the students could open up and talk about their thoughts and feelings regarding their gap-year experience. The topics for discussion included: motive for taking a gap year; activities during the year; expectations of the year and whether fulfilled; and financial issues.

Gap-year activities of geographers

Three students spent time working and travelling. In contrast Helen had worked full time as a livein volunteer at an activities centre. She found this very demanding, had little spare time and was paid very little. Emma had worked for two years after a change of university; she remembered the long hours of bar work but also the higher responsibility awarded. Matthew's gap year combined A-level retakes and paid employment. Glen and Phil visited Western Australia. Phil's travel was subsidised because he was with a theatre-group tour. Glen was born in Australia and wanted to return to his roots. Both of them had to work in the UK before setting off and to some extent work again in Australia and New Zealand. They might be seen as taking a typical travelling-backpacking 
gap year. Malcolm's gap year was somewhat different from the others in that he felt obliged to take one after he was disappointed with examination results at the end of his second year at university. He decided to take a year out, get paid work, gain maturity and a sense of direction, and then retake his examinations the following year, rather than go straight to re-sits during the summer. Malcolm took five jobs in the UK and spoke of the experience of working with a great many different people. The lesson here is to avoid stereotyping the origins and form of the gap year; the activities and combinations of activities were very wide; a few are home based while most are away from home for at least a period of time; paid work predominated but unpaid voluntary work is also found. One must also avoid stereotyping the effects of a gap year.

Reasons for taking a year out

The members of the focus groups reported a wide range of motives for taking a gap year out. These included:

- $\quad$ fashion (following the crowd; "everyone at school was taking one");

- $\quad$ fed up (with school and academic work);

- fun (excitement and experiencing something different);

- forced (by academic setback rather than as a voluntary decision; making the best of an enforced year out);

- feeling one is not mature enough for university (the gap year as a specific remedy rather than an experience with useful side-effects);

- those who chose to work to save money they needed for university; those who worked only to fund travel; and those who worked for work's sake (career benefits, in effect).

One must avoid over-generalising geography students' motives for taking a gap year. Each student demonstrated a different combination of these individual reasons. 
The benefits of a gap year

The geography students believed that there was a maturity that came from the experience of taking a gap year. Comments such as "we get on better with second years" came from several of these first-year students who felt they had grown up more quickly. They felt they had bridged the transition between school and university more fully than those who had not taken a gap year. The experience of meeting many new people in different environments and situations was felt by several to have helped them mix better at university and develop their social skills in order to make friends more easily. The second-year students with whom they got on better are the group they would have been with if they had not taken a gap year. Maturity develops during the first year at university as well as on a gap year. We do not know whether the maturing due to the first year at university is quantitatively or qualitatively different from that obtained during the various types of gap year.

Problem solving was something else that many of the students felt they had been able to develop more effectively. There was a general feeling that skills such as these would be far more useful when it came to finding a graduate job than many of the things they will learn during their degree course. Emma placed more emphasis on her improved time management. Working long hours she had learned to juggle her time in order to maintain a social life around her work. She also felt that the wide cross-section of people she had met through her different jobs had enabled her to become a better team player and get on more easily with people. Their money management had improved eventually despite (or because of) not having much of it. We can note that these are all qualities for geography graduates emphasised in the Geography Benchmark Statement (QAA, 2000). The students struggled to remember the problems they had encountered along the way. They were overoptimistic about being able to save to fund travel and for university. Emma and Helen spoke of the repetitive nature of many of their tasks at work, which motivated them to get a degree and a graduate job. Losing contact with friends was a concern for several of them, though having the 
time to visit friends around the country in other universities was advantageous. Home sickness was an early issue for the travellers but one that soon faded as challenges appeared. Those who had travelled extensively wished they had saved more. Those who had worked hard wished they had travelled more.

Advice for future gap-year students

There was great enthusiasm towards taking time out. The over-riding comment was "Just do it". They all felt that it was a hugely enjoyable and worthwhile experience which they would recommend to anyone. Helen felt that gap years should perhaps be compulsory. There was ambivalence on the degree of independence. Glen and Phil said it is good to avoid travelling on the main tourist routes, particularly in Australia. They felt that the number of British travellers and tourists spoiled it a little as they felt they were not seeing new things and meeting new people. There are important benefits (not least in terms of safety and assuaging parental worries) in going with one of the commercial providers, but meeting the challenges of "doing one's own thing" was recognised as important and for that it was imperative to go one's own way. Unhelpfully the selfconfidence to do that was seen by the students as being at its greatest towards the end of the gap year.

It was clear that the main benefits identified by the students were independence, maturity and personal responsibility for the gap year, as well as the need to be flexible and socially adept. In these Geography Benchmark terms, the gap year delivers benefits for the departments on the evidence of the students' evaluations of their gap years. 
Overall the focus groups caused the authors to revise their views of gap years. The stereotype of the backpacker was shown to be only one of several types of activity during the year out and rarely the dominant one. Combinations of different activities during the year were far more common than expected. Combinations involving living away from home (to travel or work) were seen by the students as effective for developing independence unlike a wholly home-based year. Travel and paid work both developed money-management skills in a way that the minor part-time jobs often held before the gap year did not.

\section{GAP-YEAR PROVIDERS' VIEWS}

During this section of the research interviews were held with the nine largest firms providing gap years and the most influential organisations promoting gap years. The format of the interviews was a semi-structured telephone conversation with a senior representative from each organisation. The main themes discussed with each respondent were:

- $\quad$ perceived benefits of taking a year out;

- $\quad$ problems that people face;

- the future of the gap-year market.

There are a number of different roles to be played within the gap-year industry. There are organisations to provide the opportunities to travel, volunteer or work. Some groups organise complete packages - travel, accommodation, activities, work, leisure and advice on all aspects of the gap year for the students and their families. There are companies which provide support in the form of air tickets or backpacking equipment. There are also insurance companies and job agencies. The Gapyear Company (gapyear.com) and www.gap-year.com are similar in that they provide a market in which the other providers can work. They act, as their websites show, as emerging hubs to the industry and, along with the Year Out Group, are emerging as spokespeople 
for the sector in terms of training, advice and lobbying (Parliamentary Debates, House of Commons, 1997-98).

Perceived benefits

On the whole, the providers saw the same main benefits from taking a gap year as the admissions tutors and the students. The primary benefits were the main life skills, developed before embarking on a university course, and simply not capable of being taught in schools - particularly initiative, communication skills and decision-making. The Year Out Group spoke of the gap year as an opportunity for 'accelerated personal development'. Gapyear.com predicted that people will increasingly pursue 'portfolio careers'. This means that the transferable skills will become more important than the technical skills specific to one job or degree subject. Gapyear.com felt that by taking a gap year people may give themselves the time they need to make the right decisions getting off the educational conveyor belt for a while. The providers indicated that people develop noticeably through their time out, and that at the end of a year away, the students come back into the education system better prepared and more highly motivated. This in turn, they argued, is likely to produce better students, who are likely to get better grades and be more interested in what they are studying. In a degree like geography, this is especially so, with the experiences that people have while travelling (an awareness of others and of the world) becoming particularly useful when studying other cultures and environments.

The providers identified a key benefit of a gap year as being the opportunity to gain the skills required to live away from home. It is true that not all gap years will involve living away from home, but it was argued that during the course of most years out such skills as money management, time management and self discipline would form an essential part. Such skills would be likely to help them settle more quickly into life at university. Building an appealing curriculum vitae is of 
great importance to young people in a competitive job market. With an increasing proportion of young people now obtaining degrees, the importance of non-academic skills is being recognised by employers to a greater extent. Furthermore, the activities undertaken during a gap year can be viewed as an individual statement which fulfils particular personal objectives identified by the student and the experiences and skills gained add a distinctive favour to that person's profile.

Problems that people face

The gapyear.com annual report showed that finance was the single biggest worry among young people about the gap-year experience. The providers' view was that:

(i) the costs are exaggerated;

(ii) fund raising is possible and is a valuable skill in its own right;

(iii) some gap years need not involve travel or great expense (Gapyear Company, 2001).

Trekforce spoke of their disappointment that the majority of their clients tended to come from an independent schools background. However, there were also some indications that recruitment by some organisations was directed at this group of people from wealthier families, with peer pressure to take a gap year.

The next most common worry concerned medical attention and the possibility of picking up a disease or infection. Trekforce said that this was very rare and that there are very strict regulations to ensure that problems are not common. Most students embarking on a placement are trained in basic first aid, and medical centres tend to be provided on many schemes. One respondent also talked about how medical problems occur everywhere, and that dangers are present at home as well as abroad. 
Further problems identified by the providers included the common disparity between students' expectations of the gap year and the actual experience. However the Year Out Group indicated that the rate of failure for gap years, where students prematurely withdraw or are completely dissatisfied with the experience, is very low (less than 5 per cent). The naivety and trusting nature of some students can lead to problems in some circumstances and in many cases people are insufficiently prepared for the range of different cultures they might experience when travelling abroad.

Nevertheless, providers recognised that risk was inherent in many gap-year experiences and indeed acted as part of the attraction for many people.

Development of the gap-year market

There was a consensus among the providers that the market is growing and changing every year. Despite the increasing financial problems that students are inevitably facing due to university fees, the number choosing to take a year out is continuing to grow. It is possible that this may be as much to do with the fact that people are seeing the chance to take a year out as more of an opportunity to save money before they leave for university. Project Trust reported that they felt the market was growing due in part to more active recruitment by gap-year providers at careers fairs and in schools. Some schemes have now been running successfully for over 30 years, and so parents are likely to be more trusting of these longstanding companies. They also felt that the increasing ease with which people can travel abroad has been a major factor in the growth of the industry. This has allowed many more people to travel independently. The packaging of the gapyear (planned itinerary, company reputation to diminish worries, a single payment, greater certainty of outcome) was the companies' favoured mechanism for appealing to a wider market of students and their parents. Gap-year.com felt that the growth of the Internet had also helped the gap-year market to grow. Information is available far more widely than previously and it is easy to compare the different providers. They also felt that the gap year was seen by the travel industry as the next 
major boom and so efforts are being made to make it more accessible to the public - special travel insurance packages, for example. It was also claimed that students who had simply worked for some or all of their year out were at risk of under-selling themselves in the sense that they took lowskilled jobs such as stacking shelves in supermarkets rather than a job that would teach them more important business skills. The Year Out Group echoed many of these comments but also added that the four basic themes for gap years were unlikely to change, namely skills-based activities (gaining further languages/qualifications), volunteering, work experience and travel. Overall the providers were bullish about the sector's prospects and have clear strategies for expanding the market, but their 'gap-year product' will be different from the ones sold now.

\section{LESSONS FOR GEOGRAPHY DEPARTMENTS}

A number of lessons for current departmental practice can be drawn from this research.

Students can benefit from the experience of the gap year; but by how much depends on the nature of the year. When questioned, all the students could identify the benefits pertaining to them. The benefits they identified mapped across clearly to some of the 'softer' or 'harder to instil' qualities of the geography graduate required by the Geography Benchmark Statement.

The benefits from a gap year should be recorded on students' progress files as soon as they arrive at university, so departments need to create a structure which reminds their gap-year students to record (and shows them how to record) the effects on them of the gap years they took before coming to university. The university progress file should look to the period before starting university to record the students' baseline for higher education. Similarly if the gap year follows graduation students need to be encouraged to maintain this progress file after they have left university. 
If a gap year is beneficial (say, in terms of Dweck's self -efficacy beliefs) then the fact that some of a department's intake will have taken gap years and some will not, leads to a more complex situation for departments. It adds an additional dimension to the already wide range of experiences, skills and backgrounds of Year 1 students. It is valuable for departments also (as distinct from their students) to audit their gap-year students to see what they did and how the experience affected them. Departments may also want to reflect on how this better understanding of their students prior to university might be reflected in their teaching programmes. Given the personal development effects of a gap year, its consequences are most likely to be felt in those forms of teaching that emphasise projects, self-directed learning, fieldwork and problem-solving approaches. A gap year may well have enhanced students' capabilities in these areas, compared with Year 1 students straight from school. Staff need to be aware of this likely range of personal development and practical competencies (in addition to variations in subject knowledge) when planning teaching in Year 1. The gap year compounds the 'mixed ability' aspect of preparing Year 1 geography modules.

The wide range of gap years implies that students will have matured in different ways and to variable extents - there is no standard gap-year student who is different from those straight from school in a predictable set of ways - and this makes curriculum planning more demanding. The effects of a gap year will be influenced by the balance of paid work and travel, whether living at home or independently, the kind of work and the degree of 'packaging' to the gap year.

Departments need to guard against stereotyping gap-year students.

\section{SOME PARADOXES OF EXPANSION}

Universities are rarely opposed to gap years and often welcome them. The number of students who want to take a gap year far exceeds the number who do (Gap Year Company 2001). The gap-year providers are often fairly small-scale operators and there are no insuperable commercial or 
academic barriers to the gap-year market expanding, though higher tuition fees may become an issue after 2006. However, any such expansion, fuelled by rising family incomes, would highlight several paradoxes.

Many of the benefits from a gap year come from the planning phase (financial and route planning, organising work and accommodation, safety issues, fund raising) as much as from actually living through the gap year. If the expansion of the gap-year market forecast by the providers (though possibly tempered by higher university fees) is produced by selling increasingly packaged gap years (as the providers predict), then the benefits individuals from taking a gap year will be diminished as the market expands. They will miss out on some of the research for the year, the detailed planning and sense of discovery. Some of the detailed budgeting is reduced by the single payment for the package. Options and free time may be built in, yet a package is a more structured environment. To the extent that 'structured' is equated with 'supportive', the packaged gap year may appeal to concerned parents, but the benefits of having to solve one's own problems is reduced. In these senses packaging may reduce the opportunities for personal development and independence.

The potentially most profitable section of the gap-year market is the one involving long-haul travelling. While fund raising for such gap years can be a valuable experience, this is the least socially inclusive type of gap year but has the highest 'fun and adventure' element. While universities might value gap years for their personal development potential, 18-year-olds may see them in a more hedonistic light which may limit the expansion of equally valuable but less funpacked types of gap year (e.g. volunteering). Both commercial providers and the new gap-year students may shun cheaper, more local forms of gap year. Who will promote such gap years, with their lesser profit potential? Geography departments could counsel potential gap-year students on the benefits of all types of gap years and particularly the benefits of years with a mix of travel, independent living, volunteering, paid work and skills enhancement. This advice should ideally be 
reaching the students in the Sixth Form, while they are planning their gap years and the transition to university.

We may hypothesise that an inverse-care law exists in the gap-year market. Those who take gap years tend to have high 'social capital'; that is, they have supportive backgrounds, know others who have taken a gap year and have the initiative and finance to organise one. The students who need most the benefits of a gap year will be the least equipped financially and have the least parental and school support. The danger is that gap years expand the range of self-beliefs and abilities with which students enter university, making the geography tutor's job more difficult. Gap-year students have gained in self-esteem as much as in key skills - our respondents confirmed they had compared with other students. If more people take a wider range of gap years (not just the highcost, long-haul ones) this polarising effect will diminish. When there are only a few gap-year students, they can perhaps be ignored in terms of curriculum planning. The more the gap-year experience becomes the norm, the more tempting it is to alter Year 1 to match their higher abilities. This would then move the focus to the potentially unmet needs of those who have not taken a gap year. This places the gap year in a comparable position to the current interest in accessible and inclusive curricula for the disabled (Geography Discipline Network, 2004). There is a need for a curriculum which can stretch the more able and experienced as well as developing the less able, at a time when there is a widening range of abilities and experiences among those entering university.

There is a consensus of belief in the benefits of gap years among providers, students and admissions tutors, but all these parties have some degree of self-interest in agreeing with this view. This does not constitute evidence that the students now have greater competencies than before their gap year (although post hoc the students believed they had) nor does it show that only a gap year can work this transformation. There is a lack of quantitative evidence as to the effects of gap years at university and subsequently. If gap-year students in Year 1 at university get on better with the more 
mature second-year students, have they developed further than their school cohort who went straight to university and matured in first year rather than on a gap year? If that is not the case, then the gap year has conferred no additional benefits; one simply enters the labour market a year later than one's contemporaries. On the other hand if the benefits of the gap year let students get more out of both Year 1 and later years at university and get better jobs, then the investment in the gap year was worthwhile. The prospect of higher and eventually variable university tuition fees will probably make it more important for all but the wealthiest to assess carefully the benefits obtainable only from the gap year.

Furthermore, a gap year may also be taken at the end of the undergraduate degree. This research has covered only the 'before-university' type of gap year. Are later gap years similar to the preuniversity ones or different in terms of activities and effects/benefits? For the authors to answer these questions one would require a longitudinal study on a scale greater than was possible here. One might speculate that the post-university gap year would do less for developing autonomy (already improved by the degree experience) but might be more directly career-useful if focused on relevant work experience which applies subject knowledge at degree level. A comparison of the effects of pre- and post-university gap years would be a useful next step.

More research is clearly needed if we wish to substantiate the consensus of confidence currently expressed by universities, students and providers in the many academic and career benefits of geography students taking a gap year. 


\section{ACKNOWLEDGEMENTS}

The authors gratefully acknowledge the financial assistance towards this research of Lancaster University's Teaching Quality Enhancement Fund. Many thanks are due to the large number of individuals in the following organisations who have generously helped in the undertaking of the project: gapyear.com, gap-year.com, Greenforce, Project Trust, the Royal Geographical Society, The Year Out Group and Trekforce. We are indebted to the following members of Lancaster University (the geography students who took part in our focus groups, departmental admissions tutors and Jess Gillison, Undergraduate Admissions Officer) and to two anonymous referees.

\section{REFERENCES}

Association of Graduate Recruiters (1995) Skills for Graduates in the $21^{\text {st }}$ Century. London: Whiteway Research.

Chalkley, B. (2000) Improving students' skills through work-based learning. Cheltenham: Geography Discipline Network.

Clark, D., Healey, M. J. \& Kennedy, R. (1990) Careers for geographers. Journal of Geography in Higher Education, 14, pp.143-155.

Dweck, C. (1999) Self-Theories: their role in motivation, personality and development. Philadelphia: Psychology Press.

Gapyear Company (2001) The GapYear Report 2001. Ipswich: Gapyear Company. 
Gardiner, V. \& Hughes, K. (2000) Improving students’ problem-solving and thinking skills. Cheltenham: Geography Discipline Network.

Geography Discipline Network (2004) Inclusive Curriculum Project.

www.glos.ac.uk/gdn/icp/index.htm

Jenkins, A. \& Healey, M. (1995) Linking the geography curriculum to the worlds of industry, commerce and public authorities. Journal of Geography in Higher Education, 19(2), pp.177-249.

McManus, I. C. (1998) 'Factors affecting likelihood of applicants being offered a place in medical schools in the United Kingdom in 1996 and 1997: retrospective study', British Medical Journal, 317(7166), pp.1111-1116.

Parliamentary Debates, House of Commons, 1997-98, vol. 315, 1 July 1998, pp275-93.

Quality Assurance Agency (2000) Geography. (benchmarking statement) Gloucester: QAA.

Royal Academy of Engineering (n.d.) The Year in Industry: employment opportunities before university. London: Royal Academy of Engineering.

UCAS web page (2001) Press Release

http://www.ucas.com/new/press/archive/news2001/gap120901.html (accessed 2 April 2003)

Vandome, N. (2002) Taking a Year Out. Exeter: Cromwell Press. 
Year Out Group (2000) An Introduction to the Year Out Group. Easterton, Wiltshire: Year Out Group.

Yorke, M. \& Knight, P. web page (2002) Employability Through The Curriculum.

http://www.lancs.ac.uk/users/edres/research/skillsplus/ (accessed 2 April 2003) 